\title{
Communications
}

\section{Académies suisses des sciences}

\section{Prix Média 2017}

Le Prix Média 2017 est décerné à Jean-Daniel Bohnenblust et Sophie Gabus pour leur reportage intellectuellement et émotionnellement stimulant «Poisons, venins, toxines: les animaux qui soignent».

Le journaliste Jean-Daniel Bohnenblust et la réalisatrice Sophie Gabus ont réussi, sur la base de recherches approfondies, à mettre en scène un secteur novateur des sciences appliquées. Ils ont créé un monde d'images qui laisse plus d'une fois le public ébahi.

Venin de scorpion, de serpent, de corail. La lauréate et le lauréat ont plongé dans l'univers des toxines d'origine animale et ont trouvé ce qu'ils cherchaient: des scorpions dans des caisses de laboratoire, des coraux dans des bassins artificiels. Ils ont également découvert des chercheuses et des chercheurs passionnés qui travaillent sur des agents thérapeutiques que l'on connaît depuis longtemps comme des poisons nocifs et non comme de potentiels médicaments. MorOtelles à haute dose, des toxines animales pourraient pourtant, en quantité infime, être utiles à l'homme.

Le jury du Prix Média récompense la manière réfléchie d'aborder un thème brûlant, celui-ci étant traité de façon à la fois pertinente et originale. Novateur et surprenant, le regard porté sur des laboratoires méconnus permet de mettre en lumière un thème jusqu'ici largement ignoré par le public. Les scientifiques au sein du jury jugent ce reportage instructif et d'une excellente qualité scientifique. Diffusé pour la première fois dans l'émission « $36,9^{\circ}$ » de la RTS, il a aussi été présenté aux téléspectateurs alémaniques dans le cadre de l'émission «Puls».
Caisse de secours

des médecins suisses

\section{Contributions reçues}

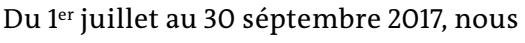
avons reçu 18 dons d'une valeur totale de 31225.00 francs.

Le Conseil de fondation de la Caisse de secours des médecins suisses est très content de pouvoir publier ces chiffres et tient à remercier vivement tous les donateurs. Afin que les contributions puissent être versées entièrement aux destinataires, nous avons pris la décision de renoncer à l'envoi de lettres de remerciement pour les dons inférieurs à 500 francs. Nous espérons que les donateurs feront preuve de compréhension et nous leur adressons encore une fois nos remerciements.

Le trésorier du Conseil de fondation

\section{Sujet d'actualité en ligne -} www.bullmed.ch/fr/tour-dhorizon

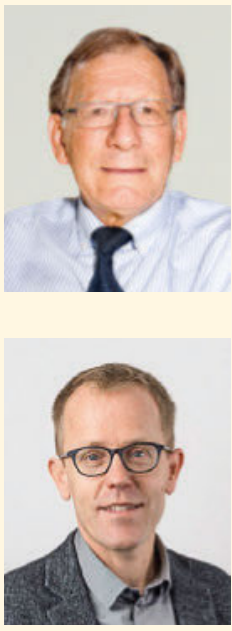

Jean Martin, ancien médecin cantonal vaudois, membre de la rédaction

\section{Lettre à Ignazio Cassis}

En toute amitié, avec des espoirs...

Interview de Dr méd. Philip Bruggmann, Stratégie Hépatite Suisse

\section{«Les connaissances relatives à l'hépatite sont insuffisantes»}

Le corps médical devrait dépister davantage et réaliser des traitements précoces. 